\title{
The Usage of Pedagogical Tasks to Improve Students' English Speaking and Listening Skills in the Saudi Context: How effected is it?
}

\author{
Professor. Al-Mohanna, Ayedh Dhawi Mohammed \\ Civil Studies-English Division King Khalid Military Academy P.O.Box: 22140 - Riyadh: 11495
}

\begin{abstract}
In the field of English as a second/foreign language, the use of tasks (communicative activities) in language pedagogy gained a great importance all around the world. It has a long history, particularly in the communicative approach to language teaching. These tasks were often called "communicative activities" and the term has been gradually replaced by "tasks".

From this prospective, the present study aims to investigate the effect of using pedagogical tasks on improving the speaking and listening skills among university-level students who study general English course at the Preparatory Program Deanship (PYD)-Imam Mohammed Bin Saud University-Riyadh City.

For the purpose of this study, the researcher randomly selected two groups of students: experimental group and control one. Then, he asked the experimental group students to perform a number of pedagogical tasks along with their English course, while he did not give the control group students any pedagogical tasks to perform. The researcher conducted a test for both groups, before and after conducting the study. Furthermore, he re-tested the experimental group for a third time in one month from the second test. The post-test results showed that the experimental group scored higher grades compared to the control one.
\end{abstract}

Keywords: English course, listening skill, pedagogical tasks, speaking skill, Saudi Arabia 